\title{
Ernst Bloch: esperanza, misterio y acción
}

\author{
Ernst Bloch: \\ Hope, Mystery and Action
}

\author{
Cossette Galindo Ayala \\ Programa de becas posdoctorales de la UNAM \\ Instituto de Investigaciones Filológicas
}

\begin{abstract}
RESUMEN: En este artículo se intenta plantear un paralelismo entre algunos elementos centrales de la literatura apocalíptica judía y la obra El principio esperanza de Ernst Bloch con el fin de encontrar similitudes y diferencias entre un modelo utópico religioso y un modelo utópico secular. Dentro de la literatura apocalíptica encontramos una particular dialéctica que es propia del pensamiento judío y que funciona entre los polos mito/historia, mística/profecía, mesianismo/ley. Nuestra tarea será detectarlos en el ideario del filósofo judío alemán como parte de la herencia bíblica en Occidente.
\end{abstract}

ABSTRACT: In the present work, we'll suggest a parallelism between some central aspects of the apocalyptic literature and the main work The Principle of Hope by Ernst Bloch, in order to find similarities and differences between a religious utopic model and a secular utopic model. Through the apocalyptic literature we found a particular dialectic that works within the poles of myth and history, mystic and prophecy, messianism and Law. Our task is to discover them along the philosophic itinerary of Ernst Bloch as part of the West biblical inheritance.

Palabras Clave: Ernst Bloch, marxismo, escatología profética, apocalíptica, mística. KEYWORDs: Ernst Bloch, marxism, prophetic eschatology, apocalyptic, mysticism. ReCiBIDO: 27 de febrero de 2017 - AcEPTADO: 17 de abril de 2017 



\section{Cossette Galindo Ayala}

Programa de becas posdoctorales de la UNAM

Instituto de Investigaciones Filológicas

\section{Ernst Bloch: \\ esperanza, misterio y acción}

Quisiera comenzar con el recuerdo de lo declarado por Martin Buber acerca de "la visión de lo justo", tanto desde el punto de vista de la "revelación" como desde la "idea". En la "revelación", la visión de lo justo se consuma en la imagen de un tiempo perfecto (escatología mesiánica), que trasciende lo social pues se ocupa del hombre en tanto creación, abarcando, por tanto, lo cósmico, mientras que en la "idea" la consumación se refiere a la imagen de un espacio perfecto (utopía), que se circunscribe al ámbito de la sociedad, como convivencia humana en un orden justo. Para Buber, ambas visiones, aunque mantienen una relación crítica con la situación actual, también intentan mostrar la "fuerza luminosa del absoluto" que logre inspirar y encaminar la acción desde el presente: "La escatología, si es profética, y la utopía, si es filosófica, tienen carácter realista" (Buber 1955: 18). Comprender las afinidades y diferencias entre ambas nos permitirá reconocer hasta qué punto el pensamiento de Ernst Bloch es un campo donde, podríamos decir, convergen revelación y razón.

En primer término, tenemos la "escatología profética" que, como puntualiza Buber, si bien confía en la intervención divina para consumar la salvación de lo creado, tiene un amplio margen de consideración de la participación activa del hombre en la construcción de un orden justo. Erich Fromm lo designará como el "alternativismo pro- 
fético tradicional", donde es el hombre quien discierne la acción justa de la injusta y decide. En segundo término, aquello que comprendemos como "escatología apocalíptica" se encuentra mucho más inclinada a la confianza en el poder de un orden sobrenatural que determina el destino de la humanidad. Esta escatología metahistórica tendrá al mito, el misticismo y la figura del Mesías como elementos esenciales para dicha consumación con un cariz marcadamente providencial (Vegas 1982: 19-39).

De acuerdo con Buber, el marxismo, a diferencia de las primeras propuestas del socialismo utópico, desembocó en una idiosincrasia de índole apocalíptica, donde la necesidad de la acción revolucionaria primó sobre las posibilidades reales y paulatinas de la acción social: "En la secularización socialista de la escatología actúan ambas por separado: la forma esencialmente profética en algunos de los sistemas llamados utopistas; la apocalíptica, especialmente en el marxismo (lo cual no quiere decir que en éste no haya penetrado ningún elemento profético; pero fue subyugado por el apocalíptico)" (Buber 1955: 20-21).

Lo que nos interesa aportar en este ejercicio de comparación es proponer que toda aquella proclamación que busca un cambio en favor de la justicia social, sea religiosa o secular, se enfrenta a las condiciones y posibilidades reales de acción en el presente, sin que pueda nunca descartar la esperanza en la llegada de un orden de justicia. Como intentaremos puntualizar aquí, aun cuando la escatología apocalíptica se refiere a la intervención de agentes sobrenaturales, persiste en ella también un compromiso con la acción humana. Aquella fe en el triunfo definitivo del bien sobre el mal, tan fervorosa como se encuentra en los escritos apocalípticos de hace más de dos mil años, es lo que alienta y encamina las fuerzas de acción reales en el panorama siempre complejo y casi desalentador de la hora presente. Consideramos que es esta herencia bíblica, la herencia de la rebelión y el Éxodo, que en la apocalíptica se traslada al ámbito cósmico, la que Ernst Bloch recupera para enfatizar la válvula escatológica del marxismo como abandono de lo estático, del reino de la necesidad hacia el reino de la libertad (Bloch 1983:67). 


\section{Mito e historia en $\mathrm{El}$ principio esperanza}

El resumen de la tesis central que Ernst Bloch propone en el prólogo a El principio esperanza considera el trabajo de Marx como la "nueva filosofía", pues su aportación más original es la categoría de lo "nuevo", de lo que nos espera, sea aniquiladora (nada) o plenificadoramente (todo). ${ }^{1}$ Esta disyuntiva en el reino de lo objetivo corresponde a dos actitudes subjetivas: temor y esperanza. Cuando la posibilidad se concreta en acción y valentía, hay un predominio de la esperanza, no como acción heroica y abstracta, sino que se pone en mediación con las condiciones dadas en la actualidad social (Bloch 2004: 293).

Sin embargo, pese a los grandes propulsores de la utopía, incluido Hegel, el principio utópico no ha logrado imponerse al mundo "mítico-arcaico" ni al "mundo urbano-racionalista", por la razón de que ambos mantienen una mentalidad "idealista-contemplativa", cuyo objeto es un mundo llegado a ser, que incluye el supramundo imaginado, en el que sólo se refleja lo efectivamente dado. Por lo tanto, la alternativa a esta actitud contemplativa de lo "llegado a ser" es la teoría-praxis que se ocupe de lo que adviene.

Encontramos la génesis de aquella actitud contemplativa y aquel apego al pasado en la anamnesis platónica: "la teoría de que todo saber es simplemente recuerdo". Marx será quien por primera vez propulse la vía del cambio como punto de partida de una teoría que no se conforma con la "contemplación ni la interpretación”. El marxismo reconoce el pasado en tanto que todavía dice algo para el futuro, "una teoría-praxis confiada en el acontecer, con la mirada fija en el novum" (Bloch 2004: 33). Aquí, la luz que ilumina el totum (utópico) en proceso inacabado será designada por Bloch como docta spes, "esperanza inteligida

\footnotetext{
La posibilidad de la nada "será asombro negativo" o aniquilación, mientras que la posibilidad del todo será "asombro positivo", precedida por el no de un "todavía no", de una realización incompleta. Ambos aspectos, la nada y el todo son componentes dialécticos mediante los cuales la dialéctica del materialismo histórico adquiere profundidad y altura: "El camino del proceso consciente de la realidad es por eso precisamente, en sentido ascendente, un camino de la pérdida del ser estático, fijado o incluso hipostasiado, un camino de la nada crecientemente percibida y por ello también, desde luego, de la utopía crecientemente percibida" (Bloch 2004: 359-361, 365).
} 
dialéctico-materialistamente", en la lucha de lo nuevo contra lo viejo (Bloch 2004: 30-31).

Podemos observar aquí una primera señal de lo que irá modelando el pensamiento de Bloch en lo que será la propuesta de una filosofía que suponemos desmitologizadora, tanto del "mito-arcaico", como del también ¡mito! "urbano racionalista”, hacia lo que podríamos entender sencillamente como un pensamiento leal a la historicidad, que concibe la realidad en términos de un acontecer siempre inconcluso. El punto crucial de esta filosofía es una cuestión de diferencia en la interpretación sobre el tiempo de acuerdo con la clase social. Tal como declara el Manifiesto comunista: "En la sociedad burguesa domina el pasado sobre el presente; en la comunista, el presente sobre el pasado" (Marx 1975: 54-55). Y "el presente", agrega Bloch, "domina, junto con el horizonte en él, un horizonte que es del futuro, y que da a la fluencia del presente el espacio específico, el espacio de un nuevo y mejor presente susceptible de ser creado" (Bloch 2004: 334). En otras palabras, el pensamiento marxista no intenta confirmar lo dado, sino derribarlo. La apertura al presente y al futuro es por tanto anticontemplativa, es activa y revolucionaria, pues comprende el mundo como un devenir, y no como un ser o un cosmos estático. Recordemos que, en El ateísmo en el cristianismo, Bloch señalará una contraposición entre cosmos griego y promesa judeocristiana, o bien, entre epifanía y revelación:

"EI", Tú eres, reza la inscripción en el Templo de Apolo en Delfos, "Eh' je ascher eh' je", Yo seré el que seré, reza la presentación de Yahvé, y no sólo en la zarza ardiente de Moisés. De aquí procede la específica, no tangible, representación del Dios de la Biblia, ajena a todo presente antiguo, aquí la diferencia entre epifanía y apocalíptica, también la existente entre la simple Anamnesis de la verdad (recordar de nuevo, el círculo) que va de Platón hasta Hegel, y la Escatología de la verdad como la de una verdad en sí mismo todavía abierta, con un todavía-no-ser (Bloch 1983: 57).

Este novum será "repetición del contenido final todavía no realizado, del contenido que se ha intentado y querido solidificar, apuntado e intencionado en las novedades progresivas de la historia" (Bloch 2004: 244). La culminación del novum será el concepto de ultimum, que es la postrera, la más elevada y fundamental repetición: la identidad. Bloch 
precisa la dinámica del comienzo y el fin, mediante la categoría del novum:

Y el final no es la recuperación, sino - precisamente como impacto de la esencia quid en el fundamento quod- la destrucción del primum agens materiale. O dicho de otro modo, el omega del "adónde" no se explicita por un alfa primigenio del "de dónde", del origen, un alfa supuestamente lo más real de todo, sino que, al contrario, este origen se explicita él mismo por el novum del final; más aún, sólo con este ultimum se hace realidad el algo esencialmente irrealizado en el origen (Bloch 2004: 247).

Señala que la categoría de lo ultimum ha sido objeto preferido de reflexión sobre la categoría del novum, particularmente en las religiones que ponen "tiempo al tiempo", como es la filosofía de la religión judeocristiana, pues en ellas se echa en ver la casi inexistente categoría del novum: "Porque en toda la filosofía judeocristiana, desde Filón y Agustín hasta Hegel, lo ultimum está referido exclusivamente a un primum y no a un novum; como consecuencia de lo cual, lo "último" aparece simplemente como el retorno logrado de un "primero", perfecto, perdido o enajenado" (Bloch 2004: 245). Aquí podríamos precisar el componente diferencial en la escatología apocalíptica judía que se alimenta del mito del Génesis como narración de los comienzos u orígenes del mundo, cuyos contenidos habrán de explicar, planificar e incluso replicar, no repetir, lo primigenio. ${ }^{2}$ Como Bloch propiamente lo entendió, la apocalíptica había heredado de los profetas, sobre todo del tercer Isaías, la expectativa de una renovación cósmica que implicaba la salida de la injusticia y la conformidad con un reino de ricos y pobres (Egipto y en lo que viene a convertirse la propia Canaán):

2 Efectivamente, Gershom Scholem explica que en el judaísmo coexisten tres tipos de fuerzas que interactúan en mayor o menor medida en todos los momentos de su historia. Mientras las "fuerzas conservadoras" se encargan de sostener y dar vigilancia al cumplimiento de la Ley para regular el comportamiento de la comunidad en el marco de la historia, las "fuerzas restauradoras" hablan de una búsqueda por recobrar un estado anterior que se considera ideal en la imaginación histórica y en la memoria nacional. Finalmente, encontramos las "fuerzas renovadoras" y orientadas hacia al futuro, que se alimentan de una visión y de una inspiración utópica donde se insertan elementos que no tienen nada de restauradores, sino que provienen de la visión de un estadio del mundo del todo nuevo, sólo mesiánicamente realizable (Scholem 1998: 102). 
Esta traslación de Canaán a lo escatológico, esta posible salida de lo prometido por Yahvé, incluso de sí mismo hacia un espacio todavía permanentemente futuro, es obra de los Profetas, que comienzan con Amós y que no terminan con Daniel. De ahí que la imagen que Isaías proyecta tiene la fuerza de un éxodo cósmico, un éxodo de la Creación anterior hacia una Creación futura [...]. Este último creator spiritus (¿es todavía Yahvé?) se traslada en el Trito-Isaías hacia un séptimo día creador, más auténtico, todavía nunca acontecido: "Mirad yo voy a crear un cielo nuevo y una tierra nueva: de lo pasado no habrá recuerdo ni vendrá pensamiento” (Is 65, 17). La salida de Egipto, la entrada en Canaán se repiten así en un nivel apocalíptico definitivo - con falsos consuelos, pero también con una revolución de palacio acerca de la imagen misma de Dios - [...]. El Paraíso del futuro que Isaías anuncia a su Dios: "No juzgará por apariencias ni sentenciará sólo de oídas; juzgará a los pobres con justicia, con rectitud a los desamparados" (Is 11, 3-4). Este Paraíso del futuro que hará a los hombres adultos no será nunca más el jardín de las fieras, con su inocencia hueca y su ignorancia (Bloch 1983: 93-94).

La utopía realizable que Bloch atribuye al marxismo tiene que ver con una ecuación donde "la teoría-praxis concreta se halla en íntima conexión con el modus indagado de la posibilidad real-objetiva" (Bloch 2004: 248). Este "correlato de la posibilidad" tiene dos lados: un reverso (la medida de lo posible en el momento), y un anverso (el totum utópico, siempre abierto). La posibilidad real es "la materia dialéctica", "el ente en posibilidad", que Aristóteles entenderá todavía pasivamente: "el seno de la fecundidad, del que surgen inagotablemente todas las configuraciones del mundo", y que llega hasta la materia creadora de Giordano Bruno. Este "semimaterialismo de la posibilidad real" se desarrolla en Giordano Bruno bajo la idea de que el mundo es realización de las posibilidades contenidas en la materia: Natura naturans (naturaleza como actividad libre, autónoma y causal de la naturaleza) y natura naturata (atributo o producto pasivo de una cadena causal infinita) coinciden, arriba como abajo "en la materia duradera, eterna, creadora, materna" (Bloch 2004: 281). ${ }^{3}$

Podríamos suponer que el debate entre una concepción activa de la materia y una concepción pasiva de la misma se remonta a la contraposición de la idea de una Creación como resultado de una hierogamia (mitos naturalistas de las religiones paga- 
El materialismo que Bloch comprende le acerca a una consideración activa de la materia, donde se espera una posibilidad de transformación y realización futura de esa misma naturaleza. De hecho, así será como Bloch designe la utopía última: "El objetivo continúa siendo la naturalización del hombre, la humanización de la naturaleza tal y como se halla implícita en la materia en desarrollo" (Bloch 2004: 252). ${ }^{4}$

Es notable que el componente activo en la naturaleza es tan importante aquí, en el proceso histórico materialista, como en las formulaciones escatológicas de la apocalíptica. Ciertamente en la literatura apocalíptica encontramos la recuperación de un principio co-creador del universo que, con un carácter marcadamente femenino, significará la presencia de Dios en la Tierra llegado el tiempo mesiánico, pero también figura anunciadora de la inminencia de esos tiempos en la hora presente. Se trata de la Sabiduría como una suerte de hipóstasis o personificación de la sabiduría divina. En el contexto de esta figura podemos encontrar ecos de una divinidad ctónica femenina y su desarrollo influenciado por el mito de la Isis helenizada. Sin embargo, la Sabiduría personificada se encontraba ya en el marco de la literatura sapiencial judía asociada con Dios en la Creación, en la forma de su "aliento o discurso", comprendiéndose como principio generador, como figuración de la vida eterna que será dada a los justos en la era

nas), donde la materia participa activamente como matriz o consorte de un creador, y una Creación ex nihilo, donde la materia es efecto de la palabra divina, y que dio su sello definitivo a la religión profética de Israel. Este debate se extendió durante la Edad Media cuando los filósofos islámicos, los filósofos por excelencia de la palabra (motakalimin), defendieron la omnipotencia de la forma suprema (del actus puros divino) que crea el mundo de la nada, frente a los filósofos panteístas-materialistas (Avicena, Averroes, Almarico de Béne, David de Dinant) para quienes "la real posibilidad material se convierte en el fundamento total del mundo, y la voluntad creadora divina es siempre un momento de la materia; más aún, Dios y materia se hacen idénticos".

$4 \quad$ La doble influencia entre lo subjetivo y lo objetivo, entre la conciencia y el ser, entre el hombre y la naturaleza, es la tesis que Bloch destaca en el pensamiento de Marx, que vino a templar los excesos tanto del idealismo aristocrático como del materialismo vulgar y mecanicista. La modificación de la naturaleza por medio del trabajo del hombre, y de éste por las condiciones materiales, hace de la utopía una labor concreta y práctica (materialismo dialéctico). Así lo explica al glosar las Once tesis que Marx elaboró en el periodo comprendido entre la redacción, junto con Engels, de La sagrada familia (1844-1845) y la Ideología alemana (1845-1846). 
escatológica e, incluso, a las generaciones presentes (Prov 8, 22-31; Eclo 24; Sab 7, 22-27).

Puesto que dentro de la apocalíptica la salvación se plantea como respuesta al dilema que embarga al ser humano desde su ínfima y mortal condición ante la lejanía y absoluta trascendencia de Dios, ${ }^{5}$ podemos comprender este principio femenino como el polo inmanente que completa el aspecto trascendente de la divinidad. Dios y su Sabiduría vienen a constituir la totalidad que es objeto del misticismo inserto en el modelo mítico que plantean los apocalipsis. ${ }^{6}$ Es la Sabiduría como

5 En el Libro de los Vigilantes (1 En 1-36) encontramos, al inicio del capítulo 9, el momento en que los arcángeles Uriel, Rafael, Gabriel y Miguel contemplan la tierra y escuchan el clamor de la "sangre inocente vertida en ella", por lo que se dirigen a Dios para comunicarle los desastres a causa de las enseñanzas que Azazel y Semyaza han transmitido a la humanidad. Los ángeles se dirigen a Dios con epítetos que acentúan su unicidad - "Señor de señores, Dios de dioses, Rey de reyes"-, así como su naturaleza eterna: "Tu trono glorioso permanece por todas las generaciones del universo; tú has creado todo y en ti está el omnímodo poder; todo ante ti está abierto y explícito; tú lo ves todo y nada hay que pueda ocultársete. Tú has visto lo que ha hecho Azazel al enseñar toda clase de iniquidad por la tierra y difundir los misterios eternos que se realizaban en los cielos; Semyaza, a quien tú has dado poder para regir a los que están junto con él, ha enseñado conjuros. Han ido a las hijas de los hombres, yaciendo con ellas: con esas mujeres han cometido impureza y les han revelado estos pecados. Las mujeres han parido gigantes, por lo que toda la tierra está llena de sangre e iniquidad. Ahora, pues, claman las almas de los que han muerto, se quejan hasta las mismas puertas del cielo, y su clamor ha ascendido y no puede cesar ante la iniquidad que se comete en la tierra. Tú sabes todo antes de que suceda; tú sabes estas cosas y las permites sin decirnos nada: ¿qué debemos hacer con ellos a causa de esto?" (1 En 9, 4-11).

Podemos advertir la insistencia acerca del aspecto trascendente del Creador y la pregunta sobre la injusticia que se desata en la tierra a causa de los ángeles-astros rebeldes y su progenie. Sin duda es uno de los fragmentos que mejor resume el problema de la teodicea, la pregunta por la injusticia y el mal en un mundo creado por un Dios justo.

6 Como expone Julio Trebolle: "El acento en la 'historia de la salvación' por parte de la teología bíblica ha marginado otras perspectivas de comprensión del mundo religioso de la Biblia, como son las relativas a la creación y la naturaleza, más relacionadas con manifestaciones teofánicas y de carácter místico. Es significativo que sean estos mismos campos que conciernen a la creación como también al mundo de lo sapiencial, los que demuestran mayores paralelismos con las religiones vecinas del antiguo Israel, mientras que la perspectiva orientada hacia la 'historia de la salvación' se centra más en los destinos del pueblo elegido. No es de extrañar, por ello, que la mística bíblica pueda tener raíces en las religiones del antiguo Oriente y que su estudio deba tener por ello una vertiente comparativa" (Trebolle 2004: 102). 
Ley profunda que ordena la Creación, como método y objeto que hace a los hombres sabios y, por tanto, justos, la que podríamos poner en una relación análoga con esa Natura naturans en que se desarrolla el materialismo histórico. El énfasis en la trascendencia de Dios, la salvación escatológica y el interés por el mundo sobrenatural, apunta a la inadecuación de este mundo para acoger la Presencia divina, pero el fin de los tiempos no equivale a decir que el mundo cesará de existir, sino, más bien, que la Creación será purificada, así como las fuerzas del mal destruidas definitivamente (Murphy 1994: 159-60).

Ernst Bloch entiende justamente la "destrucción apocalíptica" como parte del proceso del materialismo histórico que requiere la utilización positiva de la negación (de la nada) en la apertura incesante de dicho proceso:

Nuevo cielo, nueva tierra, la lógica del Apocalipsis presupone la transfuncionalización dialéctica del fuego aniquilador, tenido por satánico; todo adviento contiene en el triunfo el nihilismo como utilizado y vencido, y la muerte como engullida en la victoria. El fracaso y el aniquilamiento son, sin duda, el riesgo constante de todo experimento procesual, el ataúd permanente junto a toda esperanza, pero son también el instrumento que quiebra toda estática inadecuada (Bloch 2004: 364).

Para los apocalípticos, la Sabiduría había huido al cielo y, por tanto, el mundo estaba despojado de la presencia divina. ${ }^{7}$ Ahí se origina el dualismo que percibe una división entre este mundo corrompido y el Reino de Dios por venir, entre "esta era" - en que predomina el mal por efecto de la serpiente o los ángeles caídos - y la "era mesiánica".

$7 \quad$ En el Libro de las parábolas (siglo r a. C.), leemos, a manera de excursus: "La Sabiduría no encontró lugar donde morar, y fue su morada el cielo. Salió la sabiduría a morar entre los hijos de los hombres y no encontró aposento. Volvió la sabiduría a su lugar y se asentó entre los ángeles. Pero la injusticia salió de su cámara, encontró lo que no buscaba y moró entre ellos, como lluvia en el desierto y rocío en tierra sedienta" (1 En 42, 1-3)

8 Lo que se infiere de este desplazamiento es que anteriormente la Sabiduría era comprendida como una verdadera inteligencia material, como la generadora de justicia, bienestar, abundancia y larga vida. Sólo fue con la grave descomposición social que atraviesa Israel, primeramente, cuando sufrió el Exilio en Babilonia, y más tarde, durante la conquista del imperio helenístico, que la materialidad de la 
Ciertamente, la escatología, como noción límite de la historia, impulsa una condensación mitológica de las fuerzas sociales que se debaten en el transcurso de los acontecimientos humanos. De ahí que la escatología judía haya encontrado en el extremismo de la apocalíptica un panorama imaginativo de gran densidad. La "lucha entre las fuerzas del bien y del mal" se presenta mediante tres tipos de dualismo en el género apocalíptico: el dualismo temporal (esta era y la era por venir), el dualismo cósmico (ángeles buenos y malos), y también el antropológico (el hombre justo y el injusto), que se manifiestan en la concepción de una guerra en el final de los tiempos.

Así pues, podemos comprender por qué la propia idea del novum marxista conformara una suerte de noción límite de la historia, y que, por tanto, haya visto en la "lucha de clases" un dualismo económico que adquiere el tono de una verdadera batalla escatológica. Ernst Bloch parece ilustrar su percepción de la sociedad capitalista mediante un tipo de dualismo donde encontramos la clase de los burgueses y la de los no-burgueses, definiendo esta última mediante la ausencia de algo concluso y conforme, es decir, del síntoma inequívoco del credo burgués: "En la burguesía falta la motivación material para una separación de lo todavía-no-consciente y lo ya-no-consciente" (Bloch 2004: 173). Las dos clases se enfrentan en la raíz ética que determina la apertura o la cancelación de la esperanza: la visión del otro. Bloch distingue las dos clases de la siguiente manera: "Porque (para el no burgués) el prójimo no es el límite de la propia felicidad, sino el elemento en que ésta se verifica" (Bloch 2004: 62).

La lucha de clases del materialismo dialéctico es quizá la traducción secularizada de una batalla inmemorial por la justicia. Y continúa siendo mito en cuanto intenta abarcar a toda la humanidad y no sólo a un pueblo específico. En este sentido, la aportación de la escatología apocalíptica, respecto a la escatología profética tradicional, es que su lenguaje mítico ya no sólo se dirige al transcurrir del pueblo elegido, es decir, respecto a la historia sagrada que se observa en una perspectiva orientada a la transformación y el futuro de Israel, sino que el propio

historia deja de ser expresión de lo divino para un sector de judíos. Es comprensible entonces que estos judíos recurriesen al mito para dar forma a la catástrofe y augurar una era de reivindicación futura en el más allá de la historia. 
cosmos se escatologiza, es decir, la Creación se vuelve a comprender como insertada en el tiempo - pues ya en el Génesis estaba comprendida en el transcurrir de los siete días primordiales -, y se coloca en la expectativa de un fin, de una purificación destructora, como antecedente de transformación. Lo anterior se traduce en un axioma de universalidad, ya que, si la Creación está sujeta al tiempo, es el hombre en su condición de creatura quien se transforma y, por tanto, se trata también de la trasformación de todos los hombres en cuanto pertenecientes a la Creación.

Comprendemos entonces la dialéctica mito-historia en el entrecruzamiento de las tendencias míticas o históricas que han regido el pensamiento occidental, ya sea que provengan de una inclinación donde el mito absorbe los acontecimientos históricos para borrar lo contingente, accidentado, novedoso en ellos - tal el pensamiento griego-, o bien, de una noción de historia, según la cual los mitos (Génesis) son orientados a una consumación futura (escatología apocalíptica).

\section{Mística y profecía en El principio esperanza}

Tal como en la literatura apocalíptica encontramos un paralelismo entre la escatología histórico-cósmica y la escatología personal (referida a la vida después de la muerte de la persona), también en El principio esperanza, la función utópica sobre la historia y la naturaleza orientadas al futuro tiene como correlato la noción individual de una "conciencia anticipadora". Dicho paralelismo nos ha permitido comprender en un trabajo anterior (Apocalíptica y mística judías, una relación de interdependencia, 2013), la importancia que la experiencia individual-mística tiene para la revelación de un mundo en el final de los tiempos, de todo lo que concierne al futuro último de la historia y el cosmos. Para verificar esta relación de interdependencia nos ha sido de gran ayuda el trabajo de Paul Ricoeur (2003), cuando plantea un significado reflejo entre los "mitos del comienzo y del fin" y la "arqueología y teleología del sujeto".

Según la teoría de la tipología bíblica, inaugurada por San Pablo, y que Paul Ricoeur tiene como referente al presentar su "dinámica de los 
símbolos", existe una relación de redención entre el primer hombre, el Adán de la primera creación y de la generación pecadora, y el último hombre, el Cristo redentor de la segunda creación y de la generación salvada. Esto relatos "otorgan a esta historia un impulso, una velocidad, una orientación, al desarrollarla entre un comienzo y un fin; introducen así en la experiencia humana una tensión histórica, a partir del doble horizonte de una Génesis y de una Apocalipsis" (Ricoeur 2003: 266).

Sin embargo, para Bloch, aquel hombre primitivo sería ya imposible de rastrear, pues la supuesta "naturaleza del hombre" no tiene un origen determinado, sino que ha sido generada y regenerada cientos de veces a lo largo de la historia: "El hombre histórico no encuentra nunca, ni siquiera como salvaje, el camino hacia el hombre primitivo del que han arrancado las distintas domesticaciones actuales [...]. El 'pagano' al que el misionero bautiza, el 'viejo Adán' al que el cristiano redime, es él mismo el 'Cristo' de una religión y una moralidad anterior, es decir, de una transformación anterior de la criatura" (Bloch 2004: 97). La "intención simbólica" llevaría entonces al único arquetipo que no tiene nada de arcaico, y que es el arquetipo utópico, el summum bonum. No tiene nada de arcaico, ni siquiera de histórico, porque no ha habido manifestación alguna que responda a su imagen. No se trata (como en Platón) de una inmemorial perfección. Se trata de un "retorno al origen no manifestado", que es la génesis del alfa y el omega a la vez (Bloch 2004: 358).

Continuando con la teoría de la tipología bíblica, el Nuevo Testamento viene a significar un cuerpo simbólico que concluye la profecía del Antiguo Testamento y que si bien espera la segunda venida de Cristo (Parousia), su noción del Mesías está fijada en la figura de Jesús. Esta doctrina perdió el impulso de rebeldía política que Israel y el Jesús histórico habían heredado del espíritu de éxodo mosaico. Según puntualiza Bloch, el mesianismo sólo se convirtió en "la paciencia - o diríamos, predeterminismo - de la cruz" cuando Pablo estableció un acuerdo con los poderes de Roma y despojó al cristianismo de su principio y aliento político. Este es precisamente el sentido que Bloch reivindica en la figura de Jesús, mediante el título apocalíptico de "Hijo del hombre":

A los ojos de este mundo, quien fue colgado de la cruz no era precisamente un iluso inofensivo, sino alguien que con carácter adventista transformaba 
los valores del mundo existente, el gran modelo de otro universo sin opresión y sin Dios de los señores [...]. Jesús no era lo suficientemente pacífico para al menos poder ser tenido en cuenta como Mesías, su Reino del Hijo del hombre se situaba más bien demasiado lejos del aquel Yahvé de los señores que constantemente aparecía y legitimaba aquel que no había sacado de Egipto. El Hijo del hombre-Mesías no se mostraba tampoco como combativo sostenedor o como romántico restaurador de un mero Reino de David, con su Dios de los señores. No, él se situaba totalmente como nuevo éxodo, es decir, un éxodo escatológico-transformador desde el principio al fin: hacia Dios en cuanto hombre (Bloch 1983: 129-130).

Dentro de las tendencias apocalípticas en tiempos previos a Jesús, así la enóquica, el arco de la dinámica simbólica entre el viejo Adán y el "Hijo del hombre" no llega a ser conclusiva pues este último tipo se mantiene como una virtualidad de la realización futura o escatológica de la historia y la Creación, o como realización instantánea actualizada en la propia figura del visionario durante lo que se comprende como una experiencia mística en el transcurso de un "ascenso celestial". Así, en los apocalipsis judíos, la concepción de Dios en cuanto hombre, "Hijo del hombre", estaba ya en su impronta mística: el ascenso celestial como una suerte de reconducción en la que el hombre mortal es devuelto a su arquetipo inmortal o forma celeste plenaria, la cual, como veremos a continuación, coincide en algunos casos con el anthrophos preexistente, esto es, el Mesías mismo. De ahí que en el Libro de las Parábolas el patriarca Enoc se identifique con esa realidad trascendente que significa el "Hijo del hombre":

Llegó a mí aquel ángel, me saludó y me dijo: - Tú eres el Hijo del hombre que naciste para la justicia; ella ha morado en ti, y la justicia del "Principio de días" no te dejará. Y añadió: -Él invoca para ti la paz en nombre del siglo venidero, pues de ahí ha salido la paz desde la creación del mundo, y así será contigo por los siglos de los siglos. Todos marcharán por tu camino, no dejándote la justicia nunca. Contigo será su morada, contigo su suerte, y de ti no se separarán por los siglos de los siglos. Habrá así largura de días (en la época) de ese Hijo del hombre, y tendrán los justos paz e irán por el camino recto en nombre del Señor de los espíritus eternamente (1 En 71, 13-17). 
Y es por esta impronta mística-cósmica que Jesús, al autodenominarse "Hijo del hombre", resultó tan subversivo, pues lo que estaba significando era la posibilidad de una Creación transformada:

El Mesías era entregado a los romanos sólo cuando no era completamente nacional, o bien, cuando, en tanto que universal, no se encontraba de acuerdo con la Iglesia de la Ley. Sólo cuando el Mesías se presenta como Hijo del Hombre, en el sentido tanto precósmico como apocalíptico de este título, sólo cuando proclama como instrumento y testimonio de su triunfo una catástrofe natural que había además de destruir Jerusalén y el Templo, sólo entonces es tenido por blasfemo y digno de muerte (Bloch 2007: 384).

La singularidad de Jesús estribó en que repolitizó lo que la apocalíptica había trasladado a la esfera místico-cósmica, como visión de la transformación del hombre y de la Creación. Efectivamente la mística y la apocalíptica judías son el contexto en donde emerge el "Hijo del hombre", pero también su promesa, como preparación y vigilia constante para la llegada del Reino. Esta propedéutica del Reino, llevada a su extremo metafísico, se concibe en términos de una sociedad angélica. En ella, el anhelo del hombre justo es adquirir una naturaleza angélica, vivir de "cara a Dios" (panim ha panim), lo que podríamos entender en términos doctrinales, convertirse, o bien, nacer nuevamente cabe la divinidad. Pero este nacer nuevamente es una de las formas bajo las cuales puede interpretarse la "resurrección", entendida en términos estrictamente seculares, una capacidad transformativa en el curso de la

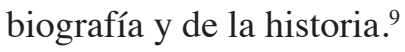

Es, pues, en la conciencia del justo donde acontece la visión de un mundo por venir que ilumina la posibilidad de la historia presente. Para

9 Tal como explica Erich Fromm: "Resurrección en su nueva significación - para la cual el significado cristiano sería una de sus posibles expresiones simbólicas - no es la creación de otra realidad después de la realidad de esta vida, sino la transformación de esta realidad encaminada a aumentar la vida. El hombre y la sociedad resucitan a cada momento en el acto de esperanza y del aquí y el ahora. Cada acto de amor, de conciencia y de compasión es resurrección; cada acto de pereza, avidez y de egoísmo es muerte. La existencia nos enfrenta en cada momento con la alternativa entre resurrección y muerte, y en todo momento respondemos. La respuesta no consiste en aquello que decimos o pensamos, sino en los que somos, en el modo en que obramos, en el lugar en que nos desenvolvemos" (Fromm 1970: 28). 
Bloch, "la conciencia anticipadora" se funda en lo "todavía no consciente", en contraposición a la noción de algo recordado y hundido en el inconsciente, como reprimido o arcaico. ${ }^{10}$ De acuerdo con la dialéctica de las hermenéuticas que propone Ricoeur, la profecía de la conciencia no es exterior a su arqueología, pero es distinta en la medida en que la figura central de la que procede el anuncio de salvación no es equivalente a la del "padre asesinado". El profeta es esa figura que se encuentra fuera de los vínculos libidinales de la familia o la cultura, y por tanto, como explica Ricoeur, es la "figura escatológica por excelencia" (Ricoeur 2003: 319). El heredero de esta figura en la literatura apocalíptica es el visionario y, en la misma línea que el profeta, su figura se sobrepone al mero "retorno de lo reprimido" en la medida en que ha dejado de estar vinculado por una pertenencia terrenal o sanguínea y se lanza a una perfectibilidad futura.

Si en el ideario de la apocalíptica existe una condición sine qua non de la experiencia mística - el ahora cualitativo - para la revelación de secretos sobre el cosmos y la historia, no resulta extraño atender a lo que Ernst Bloch expresa, inversamente, sobre la conciencia utópica (futuro) que busca iluminar la experiencia del ahora como la utopía por excelencia:

La conciencia utópica quiere ver más allá, pero, en último término, sólo para penetrar la cercana oscuridad del momento acabado de vivir, en el que todo ente se nos da en su mismo ocultamiento. Con otras palabras: para ver a través de la proximidad más cercana es preciso el telescopio más potente, el de la conciencia utópica agudizada. Se trata de esa inmediatez más inmediata, en la que se encuentra todavía el núcleo del sentirse y del existir, y en la que se halla, a la vez, todo el nudo de la incógnita del mundo (Bloch 2004: 36-37).

Si como dice Bloch en una sola frase afortunada: "la última voluntad es la de estar verdaderamente presente; de tal suerte, que el momento

$10 \quad$ Bloch argumenta que desde el descubrimiento del inconsciente por Leibniz (a través de la psicología romántica de la noche y el pasado originario) hasta el psicoanálisis de Freud, el inconsciente sólo es concebido como un crepúsculo hacia atrás. Para Bloch, la noción de inconsciente freudiana (individual), y tanto más la jungiana (colectivo) son simplemente visiones regresivas, y diríamos narcisistas, del apego a la prehistoria del útero y el arcaísmo cultural (Bloch 2004: 84). 
vivido nos pertenezca, y nosotros a él", sería justamente en la categoría temporal del instante de la experiencia mística, que es posible, tal como vemos en los apocalipsis, situarse en un tiempo que comprende el tiempo por venir. La inspiración de la utopía es entonces para Ernst Bloch un tipo de sueño diurno asentado en el "todavía-no" del inconsciente, una conciencia anticipadora de lo que todavía no ocurre. Por la forma en que lo expresa, se trata de un tipo de inspiración, no quizás sobre el advenimiento del Reino de Dios, sino de un horizonte de justicia social. De ahí que su noción de la trascendencia sea en la historia y para la historia:

Y así también es la función utópica la única función trascendente que ha quedado y la única que merece quedar: una función trascendente, sin trascendencia. Su asidero y correlato es el proceso que aún no ha dado a luz su contenido más inminente, pero que se haya siempre en curso. Un proceso que, en consecuencia, se encuentra él mismo en la esperanza y en el presentimiento objetivo de lo que todavía-no-ha-llegado-a-ser, en el sentido de lo que todavía-no-ha-llegado-a ser-lo-que-debiera (Bloch 2004: 183).

Esta "mística cotidiana" es la única que considera Bloch como digna de prevalecer en la consideración del proceso histórico y su despliegue profético-activo será justamente "la tendencia de la función utópica", la constatación realista y crítica de las condiciones objetivas del momento histórico presente, que es lo que predomina en la obra de Marx:

De lo que se trata, por eso, en la utopía concreta es de entender exactamente el sueño de su objeto, inserto en el mismo movimiento histórico. En tanto que en mediación con el proceso, de lo que en ella se trata es de dar a luz las formas y contenidos que se han desarrollado ya en el seno de la sociedad actual. En este sentido no-abstracto, utopía vale tanto como anticipación realista del bien; lo que no debería precisar más aclaraciones. Utopía en el sentido de proceso concreto se halla en los dos elementos fundamentales de la realidad conocida al modo marxista: en su tendencia, como tensión de lo que ha llegado a su plazo de cumplimiento y es impedido; en su latencia, como el correlato de las posibilidades objetivas reales en el mundo, aún no realizadas (Bloch 2006: 199-200).

Comprendemos la dialéctica mística/profecía, como una donde la experiencia instantánea de revelación de la plenitud divina da paso a 
una visión del sentido de la historia y, por tanto, de la responsabilidad con el otro. Todo profeta es místico antes de ser quien encause las fuerzas sociales, pues todo auténtico profeta se alimenta de la inspiración del Reino por venir. ${ }^{11}$ Será la integración de ambas esferas, la mística y la profética, lo que encause una cooperación constructiva entre lo individual-cósmico y lo comunitario-histórico. Es en este equilibrio que puede considerarse la mística en su estado de maduración plena. ${ }^{12}$ Podríamos resumir que, inversamente a como la escatología apocalíptica se fundamenta en una profundización del instante (visión mística) para contemplar el Reino de Dios como destino último del cosmos y la historia (profetismo), el modelo utópico secular del materialismo histórico requiere una aguda largueza de visión para comprender la plenitud del ahora.

\section{Mesianismo y Ley en El principio esperanza}

Para Ernst Bloch, la filosofía, incluso hasta Hegel, ha padecido el "síntoma burgués" de un modelo de mundo que dice cómo son las cosas y,

$11 \quad$ O de lo que Emmanuel Lévinas (1991:105) comprende como infinito: "En efecto, el profetismo es el modo fundamental de la revelación, a condición de entender el profetismo en un sentido mucho más amplio de lo que comportan el don, el talento o la vocación particulares de esos a quienes llamamos profetas. Pienso el profetismo como un momento de la propia condición humana. Asumir la responsabilidad para con el otro es para todo hombre una manera de dar testimonio de la gloria del Infinito y de ser inspirado. Hay profetismo, hay inspiración en el hombre que responde por el otro, paradójicamente antes, incluso, de saber lo que, en concreto, se exige de él. Esta responsabilidad anterior a la Ley es revelación de Dios".

12 De hecho, desde el punto de vista del psicoanálisis, la inclusión de la integridad moral y la actividad ética en el individuo es precisamente lo que distingue el misticismo de una mera patología regresiva: "La experiencia mística madura muestra así una relación íntima con la profecía. Porque si el místico muestra la autenticidad de su experiencia en su capacidad para entrar en el juego de la intersubjetividad, experimentando su comunión con Dios como indisociablemente unida al compromiso con la comunidad humana en la que se inserta, del mismo modo el verdadero profeta deja ver también que la misión histórica a la que es convocado no es independiente del vínculo íntimo que experimenta con su Dios. En definitiva, ambos no hacen sino poner de manifiesto dos dimensiones básicas del hecho religioso que necesariamente se implican y que, de un modo y otro, se hacen presentes en toda dinámica creyente. Mística y profecía se muestran así como dos componentes ineludibles y esenciales de la identidad religiosa en su conjunto" (Domínguez 2004: 213). 
por tanto, como han sido y como serán, imposibilitando así la apertura hacia la movilización social: "Para el pensamiento contemplativo $-\mathrm{y}$ todo pensamiento idealista es contemplativo - la realización se reduce a una simple 'corporeización' de una idea final, de una idea ya existente sin más y conclusa, y que el autor o artista no hace más que revestir de carne" (Bloch 2004: 232).

El concepto de conatus spinoziano, ${ }^{13}$ como sum ese conservare ("conservarse en su ser") es considerado por Bloch como un impulso que varía según cada momento histórico: "Todas las determinaciones de los impulsos fundamentales sólo tienen sentido en el terreno de su época y están limitadas a él. Ya por ello es imposible absolutizarlas, y menos aún es posible separarlas del ser económico del hombre en cada momento" (Bloch 2004: 96-98). El instinto más fundamental, por sobre la libido freudiana, será para Bloch el hambre, de acuerdo con las medidas o formas económicas de satisfacer esta necesidad en las distintas conformaciones históricas. Estas formas van siendo modificadas en el sentido de la solidaridad: "La propia conservación significa, en último término, el apetito de tener a mano situaciones más propias y más adecuadas al yo que se desenvuelve, y que se desenvuelve, sobre todo, en y como solidaridad" (Bloch 2004: 98-99)..$^{14}$

Si bien el modelo de Bloch se circunscribe a las relaciones socioeconómicas, es decir, en una línea de extensión del deseo en lo material-histórico, mientras que el modelo escatológico de la apocalíptica se inspira en la fe en un más allá de la historia, ambos coinciden en el

13 Bloch considera a Spinoza impulsor de un modelo que niega la categoría de lo posible: "La negación de lo posible, el neoestoicismo, el amor fati, se dan la mano muy afines en Spinoza: ver sub specie aeternitatis significa, por definición, ver todo lo posible como ya necesario-real. Porque, desde el punto de vista de la eternidad spinoziana, no hay - ya que coincide, como el fatum matemático del mundo, con la serie incondicional fundamento-consecuencia - nada condicionado parcialmente, es decir, no hay nada ya posible (Bloch 2004: 289).

14 Aquí podríamos agregar lo que Emmanuel Lévinas ha aportado a este deseo, como más allá de una vida satisfecha, como alternativa al célebre conatus essendi: "Quiero decir que una vida en verdad humana no puede quedarse en vida satisfecha en el seno de su igualdad al ser, vida de quietud. Que se despierte hacia el otro, es decir, tiene siempre que deshechizarse; que el ser jamás es - al contrario de lo que dicen tantas tradiciones tranquilizadoras - su propia razón de ser, que el famoso conatus essendi no es la fuente de todo derecho y de todo sentido" (Lévinas 1991: 114). 
deseo de una mejor vida, de un estado novedoso para el ser humano. El propio Bloch reconocerá el papel que tiene la apocalíptica en la concepción de una ontología abierta, una "ontología del todavía no ser de toda esencia-ser" o de una cosmología que se oriente por la escatología:

La apocalíptica, ciertamente, piensa su Escatología cosmológicamente, pero esto no es el fin de la Escatología, sino el comienzo de una cosmología escatológica, o de una ontología escatológica, para la que el ser se hace histórico, y el Cosmos se abre a un proceso apocalíptico. Esta historificación del mundo en la categoría del futuro universal y escatológico es teológicamente de una gran importancia: la Escatología se hace por su medio, el horizonte por excelencia de la Teología. Tampoco ha cerrado el Nuevo Testamento la ventana que ha abierto la Apocalíptica hacia la amplitud del Cosmos y el aire libre más allá de la realidad cósmica dada (Bloch 1983: 52)

La cosmología escatologizada o el Reino de Dios como posibilidad no consumada responde, en la apocalíptica, al tiempo en que la Creación es purificada por la acción divina y donde el hombre nuevamente es parte armónica de la misma, pero no ya como creatura inocente, sino como justo consciente de todas las penalidades. El pesimismo respecto al actuar humano, ahí donde se espera el final de la historia, no permite confiar en el curso de los acontecimientos históricos como parte de esa "medida de lo posible en el momento", de esa trascendencia sin trascendencia. No obstante, y no cesaremos de insistir en el contenido ético de la apocalíptica, el tiempo mesiánico es aquel donde las acciones justas del presente encuentran su sentido último. ${ }^{15}$

El conocimiento filosófico (o traduciríamos, místico) debe manifestarse en acción para modificar el mundo, de acuerdo con la que para Bloch es la onceava y más importante tesis de Marx. La filosofía como práctica es precisamente la aportación central del marxismo, sin contentarse con una mera contemplación de la realidad. Se trata de la transformación que modifica constantemente la estructura teórica y que hace

Tal como explica Lévinas, un mundo despojado de la acción mesiánica y dejado absolutamente en las manos del libre albedrío, guarda la posibilidad de una injusticia infinita. Pero, igualmente, un mundo dejado sólo en manos del Mesías ha cerrado ya la posibilidad de la trascendencia humana a través de la ética, de la relación con el otro. 
del marxismo una posibilidad siempre abierta, más allá de una ideología. No es, pues, bíblicamente hablando, sólo “creer en Dios", sino, más importante, "hacer su voluntad".

Y es precisamente la comunidad lo que permite una mediación que articule históricamente al individuo con el Reino de Dios o con la utopía. Dentro de la escatología profética tradicional, era siempre el pueblo de Israel, como agente social, el que sería depositario de lo prometido por Yahvé. Y aún en la escatología apocalíptica, de corte metahistórico y universalista, es la comunidad de los justos la que tendrá acceso al Reino escatológico del Mesías en el eón futuro. Se trata, entonces, de una dialéctica donde la práctica de la libertad como alternativismo profético nunca deja de estar en relación con el acontecimiento mesiánico. No así en la concepción de la Ley anquilosada que operó en tiempos post exílicos, donde la profecía se consideró concluida por la teocracia de Esdras y Nehemías y, por tanto, perdió su capacidad para alentar la rebelión, o, como lo expresa Bloch, cuando Israel abandona el "logos del Éxodo" y se entrega a "la más sometedora ascensión de la Trascendencia divina" (Bloch 1983: 69-70).

Es en la promesa mesiánica que encamina el trabajo profético, en la convergencia entre revelación y razón como podemos comprender la esperanza en Bloch: una fe que camina por la historia sin jamás convertirse en dogma o ideología de una trascendencia supremacista y solidificada. Se trata de lo que para él sintetizaba la filosofía práctica y el excepcional realismo de Marx: "la unidad de la esperanza y el conocimiento del proceso" (Bloch 2006: 199). Ahí donde se mantiene el misterio de una "esperanza en medio de la duda" y que nos lleva a actuar combativamente en favor de la justicia, no por garantía del favor de un Dios supremo, sino por el anhelo de revelación del homo absconditus, lo más próximo que aún no se ha objetivado, la identidad no encontrada.

\section{Bibliografía}

BIBLIA DE JERUSALÉN (1998). Nueva edición revisada y aumentada. Bilbao, Desclée de Brouwer.

Bloch, Ernst (1983). El ateísmo en el cristianismo. La religión del éxodo y 
del Reino. Versión castellana de José Antonio Gimbernat Ordeig. Madrid, Taurus (1a. ed. en alemán, 1968).

- (2004, 2006, 2007). El principio esperanza, vols. 1, 2, 3. Francisco Serra (ed.). Felipe González Vicén (trad.). Madrid, Trotta (1a. ed. en alemán, 1959).

Buber, Martin (1955). Caminos de utopía. J. Rovira Armengol (trad.). México, Fondo de Cultura Económica (1a. ed. en alemán, 1950).

Corriente, F. 1984. Antonio Piñero (ed.). "Libro 1 de Henoc (et y gr)", en Alejandro Diez Macho (ed.). Apócrifos del Antiguo Testamento, vol. IV, Ciclo de Henoc. Madrid, Cristiandad: 13-143.

Domínguez Morano, Carlos (2004). "La experiencia mística desde la psicología y la psiquiatría”, en Juan Martín Velasco (ed.), La experiencia mística. Estudio interdisciplinar. Madrid, Trotta: 183-217.

Fromm, Erich (1970). La revolución de la esperanza. Hacia una tecnología humanizada. Daniel Jiménez Castillejo (trad.). México, Fondo de Cultura Económica (1a. ed. en inglés, 1968).

LÉvinAs, Emmanuel (1991). Ética e infinito. Jesús María Ayuso Diez (trad. y notas). Madrid, Visor (La barca de Medusa).

Marx, Carlos y F. Engels (1975). Manifiesto del Partido Comunista, en Obras escogidas I. Madrid, Akal.

MurPhy, Frederick J. (1994). “Apocalypses and Apocalypticism. The State of the Question", en CR:BS (Currents in Research: Biblical Studies), 2: 147179.

Ricoeur, Paul (2003). El conflicto de las interpretaciones. Buenos Aires, Fondo de Cultura Económica.

Scholem, Gershom (1998). Conceptos básicos del judaísmo. Dios, Creación, Revelación, Tradición, Salvación. Madrid, Trotta.

Trebolle BARrera, Julio (2004). "La mística en los textos veterotestamentarios”, en Juan Martín Velasco (ed.), La experiencia mística. Estudio interdisciplinar. Madrid, Trotta: 99-127.

Vegas Montaner, Luis (1982). "Profetismo y apocalíptica", en El Olivo, 15, Madrid: 19-39.

- (2002). "El primer relato de la creación”, en 'Ilu, Revista de Ciencias de las Religiones, Anejos, VII: 9-33.

Velasco, Juan Martín (ed.) (2004). La experiencia mística. Estudio interdisciplinar. Madrid, Trotta. 